BULLETIN Bulletin hispanique

HISPANIQUE Université Michel de Montaigne Bordeaux

$111-2 \mid 2009$

Varia

\title{
Librerías y Bibliotecas
}

El nacimiento de las Bibliotecas públicas en España

\section{Concha Varela Orol}

\section{(2) OpenEdition}

Journals

Édition électronique

URL : http://journals.openedition.org/bulletinhispanique/1005

DOI : 10.4000/bulletinhispanique. 1005

ISSN : 1775-3821

Éditeur

Presses universitaires de Bordeaux

\section{Édition imprimée}

Date de publication : 1 décembre 2009

Pagination : 429-447

ISBN : 978-2-86781-617-8

ISSN : 0007-4640

Référence électronique

Concha Varela Orol, «Librerías y Bibliotecas », Bulletin hispanique [En ligne], 111-2 | 2009, mis en ligne

le 01 décembre 2012, consulté le 03 mai 2019. URL : http://journals.openedition.org/

bulletinhispanique/1005; DOI : 10.4000/bulletinhispanique.1005 


\title{
Librerías y Bibliotecas. El nacimiento de las Bibliotecas públicas en España
}

\author{
Concha Varela Orol \\ Universidade da Coruña - España
}

Cet article étudie la naissance des bibliothèques publiques dans l'Espagne du dernier tiers du XVIII siècle, à partir de la création des bibliothèques publiques des Universités et des Evêchés. L'article pose que ce système est clairement inspiré des réflexions de Fray Martin Sarmiento et repose sur les fondements qu'il avait établis pour sa constitution: usage public, budget annuel, personnel bibliothécaire et collections encyclopédiques. La Bibliothèque Royale de Madrid inspire largement la réglementation de ces bibliothèques.

Se analiza el nacimiento del sistema de bibliotecas públicas en España en el último tercio del siglo XVIII, a través de la creación de las bibliotecas públicas de las Universidades y de los Obispados. Se considera que tal sistema está claramente inspirado en las reflexiones de Fray Martín Sarmiento, descansando en los ejes que este habia señalado para su constitución: uso público, presupuesto anual, personal bibliotecario y colecciones enciclopédicas. La Biblioteca Real de Madrid inspira profundamente la reglamentación de estas bibliotecas.

The birth of the public library system in Spain during the last third of the 18th century will here be analyzed through the creation of public libraries in Universities and Dioceses. We consider that such a system was clearly inspired by the reflections of Fra Martin Sarmiento and was based upon the foundations he had established for his constitution: public use, annual budget, library personnel and encyclopaedic collections. The Royal Library in Madrid greatly influences the regulations of these Libraries.

Mots-clés : Bibliothèques publiques - Bibliothèques universitaires - Espagne XVIII siècle.

$B H i$, Tome 111, nº 2 - décembre 2009 - p. 429 à 447 
$\mathrm{E}$ N LOS estudios históricos se suele admitir como partida de nacimiento de las bibliotecas públicas en Espańa el decreto de 1837 disponiendo la creación de las bibliotecas públicas provinciales para recoger los fondos bibliográficos procedentes de la desamortización. Cierto es que estos estudios no dejan de señalar antecedentes programáticos como las Reflexiones literarias del P. Martín Sarmiento ${ }^{1}$, el Reglamento elaborado por Ventura Figueroa para las bibliotecas episcopales ${ }^{2}$, así como los intentos frustrados de las Cortes de Cádiz y el Trienio liberal de poner en marcha un sistema de lectura pública.

Pero ya el siglo XVIII se había abierto con la creación de la Real Biblioteca o Librería pública de Madrid y la Biblioteca pública de los Reales Estudios de San Isidro, y en el último tercio del siglo XVIII el adjetivo pública se aplica también a las bibliotecas universitarias. En 1788 Rodríguez Campomanes en su informe sobre las bibliotecas en Espańa en respuesta al cuestionario enviado por la Academia de Inscripciones y Bellas Letras de París ${ }^{3}$, afirma:

Las bibliotecas públicas se han creado generalmente en España durante este siglo, lo que debe atribuirse al ejemplo de la Biblioteca del Rey y al provecho que de su manifestación diaria resulta a las gentes literatas, por lo común pobres y faltas de medios para adquirir libros, especialmente en los primeros ańos, que es cuando pueden leerlos con mayor fruto

No será ésta la única afirmación sobre la existencia de bibliotecas públicas en Espańa antes de la desamortización de Mendizábal. El proyecto atribuido al liberal bibliotecario Bartolomé José Gallardo, pero obra de la Comisión de Biblioteca de las Cortes de Cádiz en $1813^{4}$, que tenía como objetivo establecer una biblioteca pública en las capitales de provincia, señalaba en su artículo 2o:

1. Martín Sarmiento, Reflexiones literarias para una Biblioteca Real (A referencia cultural da Ilustración española). Edición e estudio de José Santos Puerto Santiago, Consello da Cultura Galega, Col. «Base», 2002.

2. Real Cédula en que S.M. se sirve comunicar...el Reglamento hecho por... Manuel Ventura Figueroa... para el establecimiento de un fondo de que costear la expedición de Bulas..., como también de libros para una biblioteca pública en los palacios arzobispales y episcopales, Madrid, Joaquín Ibarra, 1771.

3. Justo García Morales, «Un informe de Campomanes sobre las bibliotecas españolas», Revista de Archivos, Bibliotecas y Museos, T. 75, n 1-2, 1968-72, p. 91-126.

4. Luís García Ejarque, «La Biblioteca Nacional española de Cortes y su último reglamento», en Homenaje a Justo García Morales. Miscelánea de estudios con motivo de su jubilación, Madrid, Asociación Española de Archiveros, Bibliotecarios, Museólogos y Documentalistas,1987, Apéndice I. 
El establecimiento de estas bibliotecas no obstará al de otras cualesquiera que las corporaciones o los particulares quieran instituir, ni á la existencia de las que por fortuna se hayan salvado de los estragos de la presente guerra.

En las sesiones ${ }^{5}$ en que se discute el proyecto el diputado García Zamora propone la siguiente adición a este artículo:

Sin perjuicio de agregarse á las bibliotecas provinciales todas aquellas mandadas ser públicas por las leyes, ó legadas, y que se legaren por particulares al público, que no hayan tenido efecto, ó que no lo hayan tenido qual correspondía a los deseos de la ley.

Y el diputado Silves propone:

También se incorporarán las de los ex-jesuitas que hasta ahora no hayan sido públicas ó unidas a otras que realmente y de hecho lo hayan sido.

En el texto definitivo seguirá habiendo referencias a las bibliotecas públicas ya existentes. Como ejemplo el artículo $6^{0}{ }^{6}$ :

Igualmente se agregarán á las Bibliotecas Provinciales las de aquellos cuerpos eclesiásticos o civiles, ya suprimidos, ó que en adelante se suprimieren; con tal que no estén ya destinadas por anteriores leyes á otras bibliotecas públicas.

Por tanto, las Cortes de Cádiz dan por sentado que existen ya bibliotecas públicas en España, aunque la invasión francesa tuviera funestas consecuencias para ellas, como señalan en el preámbulo los redactores del proyecto. A qué bibliotecas se refieren estos textos es la pregunta a que intentaremos contestar aquí.

\section{BIBLIOTECAS UNIVERSITARIAS Y DIOCESANAS: \\ EL CAMBIO DE PARADIGMA}

A partir del último tercio del siglo XVIII conviven en muchas Universidades españolas dos o más bibliotecas, las bibliotecas de los Colegios y la nueva biblioteca universitaria, generalmente nacida esta última con las reformas borbónicas de los estudios universitarios, exceptuando el caso salmantino, cuya Universidad se había dotado con una biblioteca universitaria con

5. Luís García Ejarque, ibid., Apéndices II e III.

6. Luís García Ejarque, ibid., Apéndice V. 
anterioridad. El modelo borbónico de biblioteca universitaria es observable en Sevilla, Alcalá, Valladolid, Valencia, etc. y también en Santiago de Compostela, Universidad que nos servirá de base para este trabajo.

Las bibliotecas colegiales son las herederas del viejo modelo de las bibliotecas universitarias medievales creadas por los colegios, las naciones, o en menor medida las facultades, aunque a veces, tal y como ocurre en Santiago, la Universidad sea quien sostiene las adquisiciones de libros, cediéndolas en usufructo al Colegio de Fonseca, en correspondencia con el modelo de asimilación Colegio-Universidad. Se trata de bibliotecas al servicio de los colegios, que se nutren de donaciones o de compras de libros esporádicas, generalmente atendidas por los colegiales, a veces con la denominación de bibliotecario, un puesto renovable anualmente como los restantes cargos colegiales, y cuyo uso está con frecuencia restringido a los propios colegiales.

Las bibliotecas universitarias creadas en España con las reformas borbónicas y base de las actuales bibliotecas universitarias en las Universidades más antiguas son hijas de un programa político de constitución de bibliotecas públicas que pensamos hay que atribuir a los círculos de poder, en gran parte formados por gallegos y asturianos, que se reunían en la tertulia de la celda de Fray Martín Sarmiento.

Es cierto que con anterioridad había sido creada la Real Biblioteca o Librería pública de Madrid y la Biblioteca pública de los Reales Estudios de San Isidro, pero el modelo de biblioteca pública como programa de desarrollo bibliotecario extendido por toda España comenzará introduciéndose en el ámbito de las reformas universitarias, aprovechando el acopio de fondos bibliotecarios que había permitido la expulsión de la Compañía de Jesús. Estas nuevas bibliotecas llevarán también en su denominación la palabra pública, y serán habitualmente denominadas bibliotecas, frente a la denominación librerías que se reserva para las bibliotecas colegiales.

Este cambio en la denominación responde a un cambio de paradigma bibliotecario. Frente a las librerías particulares y a las librerías de comunidades (órdenes religiosas, Colegios universitarios), las nuevas bibliotecas serán públicas. Ya la Encyclopédie de Diderot y d'Alembert separaba con claridad ambos tipos de bibliotecas, incluyendo entre las bibliotecas particulares las que acabamos de denominar librerías de comunidades, tales como las de la Sorbona, la del Colegio de Navarra, las de los Jesuitas de la Rue Saint Jacques y de la Rue Saint Antoine, etc., aunque la de M. Falconet ...pourroit être mise au rang des bibliothèques publiques, puisquen effet les gens de lettres ont la liberté d'y aller faire les recherches... 
En España, la transformación que supone el nuevo modelo aparece claramente reflejada en los Diccionarios de La Real Academia ${ }^{7}$. En la edición de 1726-39 del Diccionario de Autoridades se recogen ambas voces, definiéndolas en las acepciones que aquí interesan del siguiente modo:

BIBLIOTHECA. s.f. Nombre griego, que en su riguroso sentido significa el parage donde se venden libros; pero aunque en nuestra lengua se suele entender assi alguna vez, mas comunmente se toma por la Librería que junta algun hombre grande y erudito, y por las que hai en las Comunidades Religiosas, y principalmente por las que son comúnes para el beneficio público, de que hai várias en Europa, y la que tiene el Rey nuestro señor en su Real palacio.

LIBRERÍA. Se llama assimismo la Bibliotheca que privadamente y para su uso, tienen las Religiones, Colegios, Professores de las ciencias, y personas eruditas.

En la edición de 1770 aparecen recogidos ya los cambios que se estaban produciendo:

BIBLIOTECA. s.f. Lo mismo que librería; pero comunmente se da este nombre de biblioteca á la que es muy numerosa y está destinada para el uso público, como la Biblioteca real de Madrid, la del Escorial \&c.

No son las universitarias, la Real y la de los Reales Estudios de San Isidro las únicas bibliotecas que se caracterizaran como públicas. Hay una segunda red iniciada casi paralelamente a la universitaria, cuando en 1771 se mandan crear bibliotecas públicas en los Obispados, a partir de las bibliotecas de los Obispos excluidas de los expolios, y a veces también incrementadas con los fondos de la Compañía.

\section{EL USO PÚBLICO}

Unas y otras bibliotecas, universitarias y episcopales, Real Librería y Biblioteca de los Reales Estudios de San Isidro, todas ellas objeto de cuidadosos reglamentos, fueron caracterizadas por las disposiciones reales como «bibliotecas públicas». En ningún caso los decretos y cédulas de creación ocultaron que estaban dirigidas fundamentalmente a los estudiosos

7. Disponibles en http: www.rae.es 
y eruditos, siendo estos por supuesto varones ${ }^{8}$, pero su proclamada apertura al Público supone una fractura en la historia de las bibliotecas en España.

El adjetivo "públicas» aplicado a estas bibliotecas borbónicas funciona por oposición a las bibliotecas privadas o particulares, en igual sentido que señalaba la Encyclopédie. Este carácter de apertura al público es patente en los textos de sus principales impulsores:

99...Alli [en otras naciones] apenas hay lugar de forma, en el cual no haya alguna biblioteca pública, que a tales y tales horas esté patente a todo el mundo, para que a ella vayan a leer y estudiar los que no tienen libros o los que no tienen todos los que necesitan para escribir alguna obra? .

En un sentido semejante se manifestará años después Campomanes ${ }^{10}$. Además de dejar claro su carácter abierto al público en general, también señala qué público cabe esperar en estas bibliotecas:

Las bibliotecas públicas se han creado generalmente en España durante este siglo, lo que debe atribuirse al ejemplo de la Biblioteca del Rey y al provecho que de su manifestación diaria resulta a las gentes literatas, por lo común pobres y faltas de medios para adquirir libros, especialmente en los primeros ańos, que es cuando pueden leerlos con mayor fruto.

Pero este reiterado sentido de bibliotecas abiertas a todos, no debe ocultarnos que son también impulsadas por políticas gubernamentales, y

8. Las Constituciones de la Real Biblioteca de 1761 señalaban: Tampoco permitirá, que se entre en ella con gorro, cofia, pelo atado, embozo ú otro trage indecente ó sospechoso, ni muger alguna en días y horas de estudio; pues para ver la Biblioteca, podrán ir en los feriados con permiso del Bibliotecario mayor (cf. Novisima Recopilación de las leyes de España. Ed. facs. Madrid, B.O.E., 1987, Libro VIII, Tít. XIX, Ley II). En alguno de los borradores realizados para la redacción de las Constituciones de la Biblioteca Universitaria de Santiago, se recoge prácticamente el mismo texto, aunque no en la redacción definitiva: En las horas de Estudio no se dará entrada á mugeres; pues si quisieren ver la Bibliotheca, podran hacerlo en ôtras ô en otros dias con permiso del Bibliothecario Mayor (AHN, Consejos, Leg. 5470). La entrada de mujeres en la Biblioteca Nacional de Madrid será posible en 1837 gracias al informe favorable de su Director Joaquín Patiño, ante la solicitud de Antonia Gutiérrez Bueno (cf. Luís García Ejarque, La Real Biblioteca de su Majestad y su personal: 1812-1836, Madrid, Asociación de Amigos de la Biblioteca de Alejandría, 1997, p. 528).

9. Martín Sarmiento, op. cit. Todas las citas correspondientes a Sarmiento en este artículo corresponden a la Carta Segunda, y únicamente a la parte referida a las Bibliotecas públicas, que se encuentra en la edición citada entre las páginas 77 y 91. La indicación del parágrafo en estas citas, nos evita la repetición de las mismas.

10. Justo García Morales, op. cit. 
que dejan de ser consideradas propiedad privada de los Obispados o de las Universidades, como se observa ya en la documentación del período. Cuando en 1801 el Vicedirector de la Real Sociedad Económica de Amigos del País de Santiago protesta por el cierre de la biblioteca episcopal de esta ciudad, lo hace en los siguientes términos ${ }^{11}$ :

Señor, aun quando una Biblioteca Diocesana no fuera tan util, no tenía el M. R.. Arzobispo facultades para disponer de ella; pues no era suia si no del Público por la liberalidad del Rey Nuestro Señor Carlos $3^{\circ}$ de gloriosa memoria quela fundó, y dotó delos espolios que le pertenecen poniendola para maior firmeza bajo la protección de la vuestra Real Cámara de Castilla y por celadoras á las Ciudades y Cavildos...

\section{Bibliotecas públicas, BIBLIOTECAS PROVINCIALES}

Es cierto que estas bibliotecas no responden al modelo de biblioteca popular que se desarrollará posteriormente, especialmente en los países anglosajones, o con otros modelos como los gabinetes de lectura o las bibliotecas populares. Pero no cabe duda de que el reformismo borbónico en España adelantó, al igual que lo hacía en las reformas universitarias, las políticas que luego desarrollaría el liberalismo. Como señalamos, generalmente se considera el primer intento de un sistema de bibliotecas en España el atribuido a Bartolomé José Gallardo, bajo un esquema centralista tan querido a los liberales, pero la realidad es que el reformismo borbónico había asumido previamente esa tarea.

Las razonables críticas a la debilidad del sistema de lectura pública en España guardan menor relación con el modelo de biblioteca que con el hecho de que tales bibliotecas hubieran tenido que desarrollar sus servicios casi exclusivamente con los fondos procedentes de las incautaciones de bibliotecas, lo que sin duda limitó su impacto popular y les dio un carácter patrimonial/museístico. Todas estas limitaciones no deben ocultarnos que en las disposiciones referidas a las bibliotecas universitarias y episcopales nos encontramos ante las primeras políticas de establecimiento de una red de bibliotecas en España, que tendrá continuación en 1804 con la creación de bibliotecas públicas en los Colegios de Cirugía ${ }^{12}$.

11. Salvador Domato Búa, «Noticia sobre la Biblioteca Pública Arzobispal de Santiago de Compostela en la segunda mitad del siglo XVIII y principios del XIX», Compostellanum, 33, $\mathrm{n}^{\circ} 1-2,1988$, p. 291.

12. Novísima Recopilación de las leyes de España, op. cit., Libro VIII, Título XIX, Lei V. La 
El proyecto de bibliotecas atribuido a Gallardo, pero obra de la Comisión de Biblioteca de las Cortes de Cádiz en $1813^{13}$, se presenta como las bases para el establecimiento de las bibliotecas provinciales, es decir su objetivo es crear una biblioteca pública en las capitales de provincia, como claramente señala el artículo $2^{\circ}$ citado al comienzo de este trabajo.

Realmente lo que se lleva a la práctica en 1837 con los fondos procedentes de la desamortización de Mendizábal es este proyecto de las Cortes de Cádiz, creando las bibliotecas públicas provinciales ${ }^{14}$. Las disposiciones dadas en $1837^{15}$ no afectan a las bibliotecas públicas previamente existentes, como señala la orden sobre el destino de los conventos suprimidos:

No tendrán lugar las precedentes disposiciones en la capital del reino y demás puntos donde los libros y efectos artísticos de los conventos suprimidos han sido destinados á bibliotecas y museos ya existentes.

\section{Bibliotecas públicas, un PROGRAMA POLÍtico}

Dentro de los textos que inspiraron las reformas universitarias borbónicas suele aparecer alguna reflexión sobre libros y bibliotecas. Tal sucede en las propuestas de Gregorio Mayáns, Pablo Olavide y Campomanes.

Mayáns les dedica el capítulo IX de su Idea del nuevo método... (1767) ${ }^{16}$. Bajo la denominación librería, Mayáns se ocupa del cuidado de los libros,

cédula de creación de estas bibliotecas seguía insistiendo en su carácter público: Debiendo ser pública esta Biblioteca, se permitirá la entrada en ella á toda persona decente, sea ó no de la profesión.

13. Luís García Ejarque, "La Biblioteca Nacional española de Cortes...», op. cit., Apéndice I.

14. Las bibliotecas provinciales pasarán por diversos estadios para su creación. Como ejemplo, véase la información proporcionada por el Anuario del Cuerpo Facultativo de Archiveros, Bibliotecarios y Anticuarios (1882), p. 23, sobre la Biblioteca del Instituto de Lugo: Se creó por la Junta revolucionaria de 1840, agregando á la biblioteca pública que existía en el palacio arzobispal los libros de los conventos suprimidos en la provincia, estableciéndose en el Seminario conciliar, declarado por la misma Junta, Instituto provincial. Algun tiempo despues fué devuelta la Biblioteca llamada episcopal y trasladada la de la provincia á local independiente con las antiguas obras de los conventos y las modernas paulatinamente adquiridas...

15. Colección de las leyes, decretos y declaraciones de las Cortes... desde el $1^{\circ}$ de Enero hasta el fin de 1837, Madrid, Imprenta Nacional, 1837, p. 260-262.

16. Gregorio Mayáns, Idea del nuevo método que se puede practicar en la enseñanza de las Universidades de España. 1 de abril de 1767, publicado en Mariano Peset, José Luis Peset, Gregorio Mayáns y la reforma universitaria, Valencia, Ayuntamiento de Oliva, 1975, p. 173-351. 
horarios del servicio y funciones del bibliotecario, y en cuanto a sus lectores introduce estas significativas palabras:

Será pública para los graduados y estudiantes. A los graduados se dará cualquier libro que pidan. A los que estudian actualmente no se den los libros por los que se enseña en la Universidad, porque ellos deben tenerlos; ni los de otras ciencias que no profesan

El texto de Mayáns es el más extenso en relación a las bibliotecas de los aquí citados, pero no logra superar el viejo modelo de las bibliotecas colegiales, y sus disposiciones apenas distan de las que dictaban los visitadores en la primera mitad del siglo XVIII para el Colegio de Fonseca de la Universidad de Santiago de Compostela.

Pablo Olavide en su Plan de Estudios para la Universidad de Sevilla $(1768)^{17}$ presta especial atención a la composición de la biblioteca y al control que se debe aplicar a los libros procedentes de las bibliotecas de la Compañía de Jesús, con el fin de evitar sus perniciosas doctrinas. En relación con el tema que aquí nos ocupa, pocas palabras más: «Esta [la biblioteca] deberá ser pública, y respecto de que estará situada dentro de los mismos muros que el Seminario, podrá servir también para los usos de éste».

Mayores diferencias presenta la propuesta del Discurso critico-politico... ${ }^{18}$, atribuído generalmente a Campomanes y datado entre 1767 y 1775, señalando que las Universidades deberán estar provistas

...de una Biblioteca publica, y selecta, que tenga las principales obras antiguas, y modernas en todas facultades con un Bibliothecario, que sepa la Historia literaria correspondiente para poder dirigir à los Jovenes, y darles idéa de los Libros, que deben leer por su orden, para hacer un estudio util, y progresivo.

Como puede verse, se trata en los tres casos de reflexiones puntuales en el marco de las reformas universitarias, y mientras el texto de Mayáns es algo más detallado, aunque también el que mejor corresponde a la tradición biblioteconómica anterior, las pocas líneas referidas al tema por Campomanes sintetizan bastante bien lo que serán las principales bases del nuevo modelo: el carácter público, las colecciones enciclopédicas, la existencia de un

17. Pablo Olavide, Plan de estudios para la Universidad de Sevilla. Estudio preliminar por Francisco Aguilar Piñal. 2a ed., Sevilla, Universidad de Sevilla, 1989.

18. ¿Pedro Rodríguez Campomanes?, Discurso crítico-político sobre el estado de literatura de España y medios de mejorar las Universidades y estudios del Reino. Ed. por José E. García Melero, Madrid, Fundación Universitaria Española, 1974. 
bibliotecario con formación en el campo de la historia de la ciencia y la cultura, el papel de camino iniciático para la lectura y el conocimiento.

El diseño del nuevo paradigma bibliotecario que se pone en marcha en el reinado de Carlos III coincide fundamentalmente con un texto que no se relaciona directamente con las reformas universitarias, sino que es uno de los múltiples trabajos de "asesoría» realizados por el P. Martín Sarmiento. El programa bibliotecario en cuestión está incluido en la segunda carta de sus Reflexiones literarias para una Biblioteca Real, datadas alrededor de 1743, donde el benedictino plantea la creación de una red de bibliotecas públicas en España:

103... Se han de fundar bibliotecas públicas primeramente en todos los lugares en que hubiere públicas universidades. Ítem, en todas las ciudades en que hubiese catedrales; pero en donde concurriese una y otra cosa, bastará que sólo haya una biblioteca pública. Ítem, se deben fundar en los lugares populosos, aunque no tengan ni universidad ni catedral

Catedrales y universidades serán las sedes principales de las nuevas bibliotecas para Sarmiento, bibliotecas episcopales y bibliotecas universitarias públicas las instituciones posteriormente creadas.

Sarmiento está convencido que estas bibliotecas alentarán las donaciones de bibliotecas particulares para su reconversión en públicas. La importancia de este mecenazgo aparece también en otros textos del benedictino, como el informe enviado al Duque de Medina Sidonia en 1757 bajo el título Del pájaro Flamenco ó Fenicóptero, animando a las personas que puedan a que formen bibliotecas en las que en determinadas condiciones pueda entrar el público ${ }^{19}$, un sistema que había dado en Francia frutos $\operatorname{conocidos}^{20}$. Un mecenazgo que tendrá también su plasmación en España con grandes donaciones de bibliotecas particulares a instituciones públicas, bien para integrarse en otras bibliotecas, bien para constituir bibliotecas públicas. Entre las primeras podemos situar las donaciones post-mortem de las bibliotecas de Manuel Ventura Figueroa o del escultor Felipe de Castro, hombres del círculo de Sarmiento, a la Universidad de Santiago; entre las segundas las donaciones del brigadier Lorenzo Solís a Oviedo, de Pérez

19. Antolín López Peláez, Los escritos de Sarmiento y el siglo de Feijoo, La Coruña, Biblioteca gallega, 1901, p. 264.

20. Louis Desgraves, "Vers la bibliothèque publique», en Claude Jolly, dir., Histoire des bibliothèques françaises. Les bibliothèques sous l'Ancien Régime, 1530-1789, Paris, PromodisÉditions du Cercle de la Librairie, 1988, p. 391-413. 
Bayer a la Universidad de Valencia, del canónigo Pedro Antonio Sánchez al Real Consulado de La Coruña, etc.

El texto de Sarmiento ańade la «utilidad», tan querida a los ilustrados, que en el caso de las bibliotecas anticipa considerablemente el discurso con que el liberalismo llevará adelante el establecimiento de bibliotecas públicas, con fines pedagógicos, moralizantes y paternalistas, frente al analfabetismo, el alcoholismo, etc. ${ }^{21}$. Sarmiento finaliza el párrafo sobre los lugares en que debe haber bibliotecas públicas diciendo:

$103 . .$. Lo cierto es que si en los lugares que pican en mil vecinos se fundasen bibliotecas, habría en ellos menos ociosos, y no se embrutecerían tanto, por falta de libros, los que, teniendo buenos talentos, residiesen allí sin poder seguir la carrera de las letras.

Aunque podría pensarse que estamos ante el modelo de biblioteca destinada a eruditos y estudiosos, Sarmiento en su formulación parece ir más allá, no descartando funciones de recreo que se consideran propias de las bibliotecas populares, por cierto un recreo orientado en el mismo sentido que encontramos todavía hoy en los discursos bibliotecarios

$124 \ldots \mathrm{y}$, aunque haya algunos [libros] de comedias y de novelas ${ }^{22}$, también tendrán su útil, pues serviran de cebo para leer otros libros.

Falta en el texto de Sarmiento la reivindicación de la lectura como derecho ciudadano, pero este discurso, frente a lo que ocurre con la educación pública, no aparecerá en España hasta muy avanzado el siglo XIX.

Así pues, Sarmiento diseña en gran parte la política bibliotecaria que asumirá años después el reformismo de Carlos III, y en algunos aspectos posteriormente el liberalismo. Si bien es cierto que la preocupación por las bibliotecas es compartida por otros ilustrados, como señalamos, no lo es menos que las coincidencias de lo realmente puesto en marcha guardan mayor relación con el texto del benedictino que con ningún otro que conozcamos, y que es en sus textos, especialmente en las Reflexiones,

21. Para los discursos sobre la lectura en el siglo XIX, cf. Antonio Viñao, «Los discursos sobre la lectura en la España del siglo XIX», en Jesús A. Martínez Martín, ed., Orígenes culturales de la sociedad liberal (España siglo XIX), Madrid, Biblioteca Nueva, 2003, p. 85-147.

22. Se ha señalado que aún en 1843 existía la prohibición en la Biblioteca Nacional y en la de los Reales Estudios de San Isidro de leer novelas a no ser las antiguas castellanas (cf. Antonio Viñao, ibid., p. 113). Pese a que cabe interpretar que esto era indicio de las limitaciones del carácter público de estas bibliotecas, como señala Antonio Viñao, no debe olvidarse que la novela fue un género proscrito y siempre sospechoso para la censura en los siglos XVIII y XIX. Como tantas otras veces lo sorprendente es la posición de Sarmiento. 
donde encontramos un completo programa bibliotecario. El proyecto de Sarmiento no es, como se ha analizado un proyecto prematuro y frustrado, sino demorado unos años en su ejecución. El interés por estas cartas de Sarmiento seguía manteniéndose a finales del siglo XVIII, ya que después de años de circulación manuscrita, fueron impresas por Antonio Valladares en su Semanario erudito en 1789.

Estamos pues ante una propuesta de un sistema de bibliotecas extendido a lo largo de Espańa, con sede en las Universidades y Catedrales, y que Sarmiento cree que servirá también para alentar la reconversión de bibliotecas particulares en públicas.

Las relaciones de Sarmiento con dos de las figuras más importantes de la política cultural del período son bien conocidas: el jesuita, confesor real y director de la Biblioteca Real, P. Francisco de Rávago, y Rodríguez Campomanes, tertuliano de la celda del benedictino de quien recibió claras influencias, como destacó Ernest Lluch ${ }^{23}$. También en las bibliotecas, como en otros campos, «...as reformas culturais da Ilustración española, tal e como se entenderon a partir do reinado de Fernando VI, teñen a orixe no plan sistemático, organizado e coherente de Sarmiento, porque é do benedictino de onde as tomaron Rávago e mailos asesores de Ensenada, e máis tarde Campomanes» ${ }^{24}$.

Otro gallego en la Corte, Manuel Ventura Figueroa, pertenecía como Sarmiento a este círculo de intelectuales próximos al poder, a través de su relación con el P. Rávago, que será quien le otorga el importante papel que jugará en la negociación del Concordato de 1753. Figueroa está también directamente relacionado con Campomanes, redactor de su elogio fúnebre ${ }^{25}$ y uno de sus albaceas. Parece haber sido también amigo de Sarmiento ${ }^{26}$, y junto a Campomanes, el Duque de Medina Sidonia y otros, costeó el busto de Sarmiento realizado por Felipe de Castro. Pues bien, será Ventura Figueroa quien redacte el Reglamento de las bibliotecas episcopales ${ }^{27}$.

23. Ernest Lluch, Las Españas vencidas del siglo XVIII. Claroscuros de la Ilustración, Barcelona, Crítica, 1999, p. 169.

24. «... las reformas culturales de la Ilustración española, tal y como se entendieron a partir del reinado de Fernando VI, tienen el origen en el plan sistemático, organizado y coherente de Sarmiento, porque es del benedictino de donde las tomaron Rávago y los asesores de Ensenada y más tarde Campomanes». José Santos Puerto, "Introducción», en Sarmiento Martín, op. cit., p. 26.

25. ACC, pieza 27-17.

26. José Santos Puerto, Martín Sarmiento: ilustración, educación y utopia en la España del siglo XVIII, A Coruña, Fundación Pedro Barrié de la Maza, 2002, T. I, p. 215.

27. Real Cédula en que S.M. se sirve comunicar...el Reglamento hecho por... Manuel Ventura Figueroa... op. cit. 
Parece claro que los principales actores del nacimiento de las bibliotecas públicas en España hay que buscarlos en este círculo de intelectuales y políticos gallego-asturianos en la Corte, en el que Sarmiento actuó como ideólogo y Campomanes y Figueroa como ejecutores.

Desde que Sarmiento escribió su informe hasta que se ponen las bases de un sistema de bibliotecas públicas pasaron más de 20 años. Posiblemente antes era imposible llevar adelante esta política en su totalidad. Previamente era necesario realizar reformas en la Iglesia, especialmente en lo referente a la regulación de los expolios tal y como se hizo en el Concordato de 1753. Se precisaba asimismo abordar reformas en las Universidades, especialmente los dos aspectos claves de estas reformas: la expulsión de la Compañía de Jesús y la disminución del poder colegial en los Claustros.

$\mathrm{Al}$ igual que las bibliotecas incautadas por Felipe $\mathrm{V}$ permitieron abrir la Real Biblioteca, las incautadas a los jesuitas serán en la mayoría de los casos las bases de las bibliotecas públicas, sean estas episcopales o universitarias. Estas últimas no se crearon a partir de las bibliotecas colegiales ${ }^{28}$, ya que la reforma de los Colegios no estaba aún finalizada, pero ejecutada la expulsión de los jesuitas se contaba con un patrimonio bibliográfico para ponerlas en marcha.

Falta contestar a la pregunta de a qué intereses respondía este nuevo paradigma bibliotecario. Si la Biblioteca Real de Madrid hay que enmarcarla en el programa político cultural elitista correspondiente al poder político de los jesuitas en la primera mitad del siglo XVIII, las nuevas instituciones culturales corresponden al cambio de esta política coincidente con el reinado de Carlos III. Como señala José Antonio Valero ${ }^{29}$, coincidiendo con el relevo de colegiales y jesuitas, se asume el valor de la institución literaria como instrumento de «ingeniería social» con vistas a modificar las formas de pensamiento y de actuación de los súbditos, lo que explicaría el nacimiento de nuevas instituciones de puesta en marcha de una cultura dirigida activa, en el que hay que enmarcar el propio control de las Universidades, y también el nacimiento de las bibliotecas públicas .

28. Las bibliotecas de los Colegios, o los restos de las mismas, llegarían a muchas Universidades posteriormente, como ocurrió con la del Colegio de Fonseca de Santiago en 1843, o la del Colegio Mayor Reunido de Santa Cruz y Santa Catalina de Granada en 1837.

29. José Antonio Valero, «Razón y nación en la política cultural del primer XVIII», Espéculo. Revista de Estudios literarios. Disponible en: http:www.ucm.es/info/especulo/numero22/ razon18.html [connsulta 2002]. 


\section{LOS EJES DEL NUEVO PARADIGMA}

Las disposiciones elaboradas para ambos tipos de bibliotecas, universitarias y episcopales, presentan características comunes. En primer lugar las bibliotecas públicas han de tener un horario de apertura mañana y tarde para el servicio al público, lo que había servido como argumento a Sarmiento para su establecimiento, incluso donde hay bibliotecas de comunidades religiosas, ya que éstas «...no están libres y patentes para todo el mundo, por mañana y tarde...» La existencia de un horario fijo, señalado también en otras bibliotecas como la de Valladolid, Valencia, etc., caracterizará a las nuevas instituciones frente a otras bibliotecas que en determinados momentos podían hacerlo, tal y como ocurría con algunas bibliotecas de comunidades. En Santiago de Compostela, el rector de la Universidad Antonio Páramo señala a Floridablanca que, a pesar de que la biblioteca del monasterio benedictino de San Martín Pinario está franca «a toda persona decente y conocida», debería abrirse al público «...señalando dias, y horas, para que pudiesen aprovecharse todos de un thesoro, de que en él dia se utilizan tan pocos».

Para esa apertura al público recomendaba también el rector Páramo que se pusiese bibliotecario en la biblioteca del monasterio. Esto será otro de los componentes fundamentales del nuevo paradigma bibliotecario: las bibliotecas públicas han de estar dotadas de personal bibliotecario, para lo que en las universitarias y episcopales se propondrá una terna al Consejo de Castilla, correspondiendo al movimiento centralizador que el absolutismo borbónico estaba imprimiendo a las instituciones. Sarmiento había señalado ańos antes su necesidad: "...dos o más personas eclesiásticas que asistiesen en ella y la gobernasen». La cédula de 1771 para la creación de las bibliotecas episcopales mandaba a la Mitra, o al Colector de expolios en sede vacante, destinar de 400 a 800 ducados para pagar al bibliotecario.

En la Universidad, frente al antiguo modelo colegial que a veces repartía las llaves de la librería entre los colegiales, en otras ocasiones era un cargo anual, como los restantes del Colegio, se propone ahora la figura de un bibliotecario permanente. Y lo era hasta tal punto que, cuando el bibliotecario mayor de la Universidad de Santiago es expulsado de la Universidad y desterrado por su colaboración con los franceses en 1809, no es posible sino hacer un nombramiento de bibliotecario interino y no será hasta la muerte del primero cuando el nombramiento de su sucesor se convierta en definitivo.

La formación que habían de poseer tales bibliotecarios no fue una cuestión olvidada. Éstas eran las cualidades que requería un anónimo redactor de un 
borrador para la redacción de las Constituciones ${ }^{30}$ en la década de 1790 en la Universidad de Santiago:

...prudencia, urbanidad, mucha inteligencia, y manejo de la lengua latina, pericia de alguna de las doctas en especial de la Griega, y de las principales bulgares de Europa: instrucción en las buenas letras, y en la Historia Literaria, noticias de otras facultades que la de su profesion, y sobre todo conocimientos Bibliographicos.

En la Universidad de Salamanca un borrador de 1775 exigía el conocimiento del hebreo, requisito también en 1786 en el Plan de Estudios de Valencia, que añadía además el dominio de la lengua griega, y el conocimiento de la lengua arábiga por parte de uno de los bibliotecarios segundos ${ }^{31}$.

La bibliografía y la biblioteconomía, historia literaria, bibliografía en términos del período, requeridas en la formación de los nuevos bibliotecarios subrayan la exigencia formal de una especialización desconocida en las viejas librerías. Los bibliotecarios compostelanos reclamarán durante años una cátedra agregada a los bibliotecarios mayores de la Universidad, siguiendo el modelo puesto en marcha en 1785 en los Reales Estudios de San Isidro de Madrid.

El tercer eje sobre el que se construyen las nuevas bibliotecas públicas era la existencia de un presupuesto anual para sus gastos de mantenimiento y para las nuevas adquisiciones de libros. Sarmiento había establecido cuidadosamente la distribución de ese presupuesto: 200 ducados para libros, 150 al bibliotecario sacerdote, 80 ducados al bibliotecario segundo, 60 para el amanuense y el mozo respectivamente, y el resto hasta completar 600 ducados anuales para reparos del edificio, estantes y gastos de pluma y tinta.

En las bibliotecas creadas por el absolutismo borbónico también se fijará un presupuesto anual, aunque su mantenimiento deba ser asumido por otros. En el caso de las bibliotecas episcopales se establecía una parte del expolio para comprar libros. También Rodríguez Campomanes en la redacción de su Plan de estudios para la Universidad de Santiago en 1770 señalaba su existencia a costa de las rentas universitarias, y lo volverá a hacer una Real provisión de $1774^{32}$, verdadera carta fundacional de la biblioteca:

30. AHN, Consejos, Leg. 5.470.

31. Ma Cruz Cabeza Sánchez-Albornoz, La Biblioteca Universitaria de Valencia, Valencia, Universitat de Valencia, 2001, p. 113.

32. AHUS, Universidade, Serie Histórica, Leg. 188. 
Cada año al Tiempo del Avance general de las Rentas de la universidad cuidara el Bibliotecario de que se separe del sobrante de éllas aquella cantidad que le parezca poder emplearse assi en el reparo y conservación de las obras acttuales y complemento de éllas, como en la adquisición de otras de que carezca la biblioteca...

Probablemente aún existe otro eje que caracteriza al nuevo paradigma bibliotecario, al menos en las Universidades, aunque no podemos incluirlo aquí más que a modo de hipótesis debido a la carencia de estudios monográficos sobre la composición de los fondos de sus bibliotecas en España en los últimos años del Antiguo Régimen. Nos referimos al carácter enciclopédico de sus colecciones. Sarmiento había justificado la necesidad de bibliotecas públicas porque las de comunidades nunca eran «universales en todo género de libros». Y al referirse a sus colecciones bibliográficas señalaba:

124. De manera que, en dichas librerias, ha de haber libros tocantes a la lengua castellana, a la gramática y lengua latina; libros de historia, de moral, los juegos mas principales de filosofía y teología, según los más recibidos sistemas; libros de medicina y de historia natural, libros de mecánica, de agricultura, etc. ...

Si comparamos dos de los catálogos conocidos de las bibliotecas de la Universidad de Santiago, el del Colegio de Fonseca redactado en 1786 y el de la nueva biblioteca universitaria redactado en $1794^{33}$, más allá de las diferencias numéricas, se observa claramente cómo la biblioteca colegial apenas posee colecciones que no sean de Teología y Derecho, especialidades que cursaban los colegiales, escasos fondos de Filosofía y Medicina. Y esto pese a que la biblioteca del Colegio era sostenida por la propia Universidad hasta la separación de Universidad y Colegio. Pues bien, a la altura de 1794 la nueva biblioteca universitaria es una biblioteca que intenta representar todas las ramas del saber, su propia ordenación así lo indica, aún dentro del lógico desequilibrio de las colecciones teológicas, sin duda marcadas por su procedencia jesuítica. El borrador de las Constituciones de la década de 1790 ya citado señalaba la obligación del bibliotecario de constituir colecciones equilibradas, "...evitando que sobren libros en una [facultad] al mismo tiempo que falten en otra los mas necesarios».

La práctica de la especialización de las colecciones no debía ser infrecuente en las bibliotecas colegiales, si atendemos a las palabras de Campomanes ${ }^{34}$ :

33. AHUS, Universidade, Serie Histórica, Libro A 57.

34. Justo García Morales, op. cit. 
Las universidades literarias del Reino se contentaron con adquirir los libros técnicos de las facultades que se enseñaban en sus aulas.

Bien es cierto que conocemos que en algún caso las colecciones que existían en los Colegios eran enciclopédicas. En 1799 se propone la apertura al público de la biblioteca del Colegio de Santa Cruz de Valladolid porque contiene libros de todas las Facultades, frente a la pública de la Universidad, muy escasa y reducida ${ }^{35}$. Sin duda la biblioteca colegial de Santa Cruz, al igual que la del Colegio de San Ildefonso en Alcalá, no representan la biblioteca colegial tipo de las existentes en Espańa debido a la riqueza de sus fondos, pero obsérvese que también aquí su enciclopedismo sirve para solicitar su apertura como pública.

\section{LA BIBLIOTECA REAL, MODELO A SEGUIR}

Las nuevas bibliotecas son en poco tiempo dotadas de una reglamentación que había de marcar su funcionamiento. $\mathrm{Y}$ aunque probablemente tal reglamentación fue ampliamente debatida en el seno de las Universidades, al menos así ocurre en la Universidad de Santiago, la realidad es que las distintas Constituciones debieron seguir con bastante exactitud las establecidas para la Biblioteca Real de Madrid en 1761, redactadas por Juan de Santander.

El Consejo de Castilla en 1774 manda a la Universidad de Santiago elaborar las Constituciones de su biblioteca a partir de unas instrucciones de funcionamiento elaboradas por Francisco del Valle-Inclán, profesor compostelano a quien el propio Consejo había designado para llevar adelante la constitución de su nueva biblioteca, probablemente por su sintonía con las políticas reformistas borbónicas. Pero junto a estas instrucciones, la Universidad debía tener presentes las de la Biblioteca Real.

$\mathrm{Y}$ en realidad, pese a que las Constituciones definitivamente aprobadas señalen en su preámbulo otra cosa, las ordenanzas de la Biblioteca Real se copiaron casi literalmente en los aspectos técnicos, y en otros, esencialmente en los aspectos referidos al personal, fueron modificadas por el Consejo de Castilla en su largo proceso de tramitación hasta coincidir con lo realmente querido por éste. Sin lugar a dudas podemos decir que en las Constituciones de la Biblioteca de la Real Universidad de Santiago lo más significativo está

35. J. M. Ruiz Asencio, S. Carnicer Arribas, «La Biblioteca de Santa Cruz de la Universidad de Valladolid", en Historia de la Universidad de Valladolid. Valladolid, Universidad, 1989, vol. II, p. 805-811. 
en el término Real, indicador del centralismo que se imprimía no sólo a las Universidades, sino también a las bibliotecas públicas.

No fue Santiago la única Universidad donde las Constituciones de la Biblioteca Real fueron el texto base para los nuevos reglamentos. En Salamanca el Consejo manda redactar unas Constituciones el mismo año que lo hacía a la Universidad de Santiago, «...teniendo a este fin presente las Constituciones que rigen en la Real Biblioteca...» ${ }^{36}$. También en Oviedo cuando en 1782 el bibliotecario propone las ordenanzas para la Biblioteca universitaria, señala que las propuestas se hacen ...conforme a las de vuestra $R^{l}$ Biblioteca... ${ }^{37}$.

Por otra parte, los bibliotecarios reales actúan como asesores del Consejo de Castilla en relación a las bibliotecas. Así Tomás Antonio Sánchez, bibliotecario mayor interino de la Biblioteca Real, valorará las propuestas realizadas por la Universidad de Santiago en relación con las instalaciones de su biblioteca, la impresión de su catálogo, etc., y lo mismo ocurrirá años más tarde con Francisco Antonio González Ońa informando la solicitud del título de bibliotecario real demandado por el bibliotecario mayor de Santiago en 1817.

Aunque la Biblioteca Real, luego Biblioteca Nacional, no se articula legislativamente como cabecera de un sistema centralizado de bibliotecas en España hasta la planificación de las bibliotecas públicas provinciales realizada por las Cortes de Cádiz ${ }^{38}$, todo parece indicar que ya en el siglo XVIII en muchos aspectos funciona como tal.

Así pues, mientras las viejas instituciones bibliotecarias comienzan a desaparecer en un proceso que se inicia con las bibliotecas de la Compañía y que finalizará con las de los Colegios y las de las órdenes religiosas del Antiguo Régimen, comienza a ponerse en marcha un nuevo modelo bibliotecario, que parte de la creación de las bibliotecas universitarias y episcopales y continúa con el establecimiento de las bibliotecas provinciales. Desde el principio del nuevo paradigma bibliotecario la Biblioteca Real tendrá un importante

36. Margarita Becedas González, «Primeros reglamentos de la Biblioteca Universitaria de Salamanca: 1775-1776», en De Libros y Bibliotecas: Homenaje a Rocío Caracuel. Sevilla, Universidad de Sevilla, 1994, p. 37.

37. Ramón Rodríguez Álvarez, La Biblioteca de la Universidad de Oviedo. Oviedo, Universidad de Oviedo, 1993, p. 264-266.

38. Luís García Ejarque, «La Biblioteca Nacional española de Cortes y su último reglamento", op. cit. Es conocido que las Cortes consideraban Biblioteca Nacional a la establecida en las propias Cortes, pero con un papel similar al que finalmente tendrá la antigua Biblioteca Real. No será éste el único aspecto que las Cortes recogerán de la política bibliotecaria borbónica, tal y como ocurre por ejemplo en el caso de las bibliotecas diocesanas. 
papel en la unificación del sistema de bibliotecas, y fortalecerá el centralismo que el Consejo de Castilla deseaba imprimir al mismo.

Aunque sin duda el nuevo modelo suponía una fractura respecto a las bibliotecas del Antiguo Régimen, el origen de los fondos de las nuevas bibliotecas públicas marcará durante largos años su composición y paradójicamente las llenará de libros cuyos contenidos eran el mejor exponente del pensamiento del Antiguo Régimen.

\section{Siglas de Archivos}

ACC: Archivo Conde Campomanes. Madrid

AHN: Archivo Histórico Nacional. Madrid

AHUS: Archivo Histórico y Universitario de Santiago de Compostela. 
